\title{
DESCENTRALIZAÇÃO EDUCACIONAL: UM OLHAR CONSTITUCIONAL A PARTIR DO DIREITO FUNDAMENTAL À EDUCAÇÃO
}

Tatiane Campelo da S. Palhares *

\section{RESUMO}

O propósito deste trabalho é enfrentar o seguinte problema: que possibilidades a autonomia e a descentralização educacional apresentam para uma efetiva educação no Estado Democrático de Direito? Construir autonomia a partir de uma descentralização educacional implica "mudanças culturais" profundas nas pessoas. Assim, o presente trabalho objetiva discutir sobre a autonomia e a descentralização educacional. O conceito de descentralização e autonomia indicam a importância para o Estado Democrático de Direito. O método de trabalho foi o hipotético-dedutivo versando sobre o conceito de autonomia que consiste na construção de conjecturas e situações que permitem alcançar os objetivos da pesquisa.

Palavras-Chave: Democracia; Participação; Autonomia; Educação; Descentralização.

\section{EDUCATIONAL DECENTRALIZATION: A CONSTITUTIONAL VIEW FROM FUNDAMENTAL RIGHT TO EDUCATION}

\begin{abstract}
The purpose of this paper is to address the following problem: what possibilities do the autonomy and the educational decentralization present for an effective education in the Democratic State of Law? Building autonomy from an educational decentralization implies "profound cultural changes" in people. Thus, the present work aims to discuss autonomy and educational decentralization. The concept of decentralization and autonomy indicate the importance for the Democratic State of Law. The method of work was the hypotheticodeductive approach on the concept of autonomy that consists in the construction of conjectures and situations that allow to reach the objectives of the research.
\end{abstract}

Keywords: Democracy; Participation; Autonomy; Education; Decentralization.

\section{Introdução}

A participação na democracia, ao canalizar a capacidade criativa e crítica do movimento social, pode vir a ser um instrumento de dinamização e de significativas mudanças na sociedade (BORJA, 2016). Nesse sentido, a participação do cidadão em todos os espaços nos quais atuam se configura como uma necessidade imperativa.

\footnotetext{
${ }^{1}$ Doutora em Direito Constitucional pela UNIFOR. Professora do Centro Universitário de Ensino Superior do Amazonas - CIESA. tatianepalhares@ hotmail.com
}

Revista Brasileira de Filosofia do Direito | e-ISSN: 2526-012X | Belém | v. 5 | n. 2 | p. 108 - 124 | Jul/Dez. 2019. 
A participação em processos decisórios, de interesse público, independentemente do resultado do processo, e, apesar das dificuldades presentes na sociedade brasileira, contribui para participação popular no governo da coisa pública contra a arraigada tradição oligárquica e patrimonialista (BENEVIDES, 2018).

A compreensão do processo de descentralização implica em um estudo cuidadoso, pois os conceitos assumem conteúdos particulares e de acordo com o contexto sócio histórico. A existência de uma diversidade de interpretação sobre o termo descentralização e as distintas definições decorrem de uma visão de mundo social, com preocupações e prioridades diferentes. O que parece consensual é que o conceito está vinculado a um movimento de reação a uma tendência centralizadora, em favor do fortalecimento da esfera local, constituindo-se, portanto, em uma distribuição de responsabilidades entre as três esferas de governo, ou a partir de uma concepção clara de reforma do Estado (BENEVIDES, 2018).

De um modo geral, a descentralização implica na existência de uma pluralidade de níveis de decisão exercida de forma autônoma pelos órgãos independentes do centro. Para Uga (1991), a descentralização distingue-se da desconcentração, que é entendida como delegação de competências sem deslocamento do poder decisório, ou mesmo como um processo de dispersão físico-territorial de instituições governamentais, inicialmente localizadas de forma concentrada.

A desconcentração, embora necessária, não é suficiente para que os níveis desejados da descentralização na tomada de decisões sejam atingidos. Portanto, as consequências da implementação de uma ou outra categoria pode ser identificada na ameaça às estruturas consolidadas.

Lobo (2016) entende a descentralização como um movimento que trata de uma redefinição de centros de poder que, se bem colocados primordialmente no interior do aparelho do Estado, direta ou indiretamente se articulam com a sociedade em geral. Para essa autora, a desconcentração pode contribuir com a descentralização, como também, substituirlhe, cobrindo-a de uma aparência renovadora, tendo em vista que seu processo é puramente administrativo, visto que não pode adotar leis próprias.

Pereira (2015) assinala que, ao se falar em descentralização, automaticamente relacionamos à ampliação da democracia e da participação popular, como reação contrária ao autoritarismo e à centralidade. Mas, esta relação direta só pode ser feita se contemplar a 
intermediação da participação popular e do controle social, que pressupõe a intermediação das divergências sociais como instrumento da lógica democrática.

Segundo essa autora, é preciso atentar para a questão da descentralização, pois ela nem sempre significa uma redistribuição de poder para a sociedade civil por meio da participação, mas, sim, busca, em determinados contextos, encobrir a face obscura de um regime autocrático.

Assim, o trabalho objetiva analisar a autonomia dos indivíduos nos processos decisórios, partindo do processo educacional. O tema central recai sobre a sociedade democrática e a real participação dos agentes sociais para a construção de uma autonomia responsável, sem que tais agentes participem como "agentes corrimãos". O problema para reflexão no presente artigo, corresponde a identificação da ausência de participação dos agentes sociais para decretação da autonomia debatida por meio do preceito da descentralização. Por fim, o método de trabalho foi o hipotético-dedutivo versando sobre o conceito de autonomia, que está ligado a ideia de autogoverno em que os indivíduos são regulados por regras próprias, tendo como escopo apresentar resultados em face da maneira de gerir, orientar, as diversas dependências em que os homens e os grupos se relacionam.

\section{Descentralização: destaque histórico para a descentralização}

$\mathrm{Na}$ sociedade brasileira, as políticas públicas estão subordinadas aos processos de acumulação de capital expresso na concentração de rendas, de riquezas e no insuficiente desenvolvimento social, conjugado com a negação dos direitos sociais fundamentais: educação, saúde, cultura, previdência e habitação. Segundo Oliveira (2010), faz-se necessária uma análise das causas da descentralização no Brasil:

a) O período autoritário militar, implantado no Brasil em 1964, começou a dar sinais de exaustão já no final da década de 1970, formulando uma política de abertura "lenta e gradual". Verificou-se uma tendência - incorreta, na verdade - de identificar centralização com regime autoritário e descentralização com regime democrático. Incorreta porque, no caso específico da educação, tal generalização não procede, haja vista a situação do Chile, que 
municipalizou o ensino em pleno regime autoritário. A Itália, para citar um exemplo de país com liberdades democráticas, explicita o seu ensino centralizado, o que pode ser explicado por questões históricas.

b) Na década de 1980, verificou-se, no Brasil, uma intensificação nos movimentos sociais exigindo maior participação e acesso aos requerimentos públicos. Além disso, destacase que movimentos de governadores, prefeitos, secretários estaduais e municipais passaram a exigir maior participação e transparência na elaboração e efetivação das políticas públicas;

c) $\mathrm{O}$ interesse do neoliberalismo pela descentralização tem se destacado pelos governos que têm postulado a execução de uma estratégia de modernização dos aparelhos institucionais nacionais, que inclui como componentes centrais da agenda respectiva, a desburocratização, a privativatização e a descentralização.

A corrente do neoliberalismo, diferentemente do que se propaga, não descentraliza o Estado; pelo contrário, diminui os recursos e as competências concretas dos poderes locais, bem como os meios e a autonomia de funcionamento dos organismos que realizam atividades sociais (OLIVEIRA, 2010).

$\mathrm{Na}$ prática, o caráter tecnocrático-centralizador do Estado aumenta, bem como a distância das classes mais baixas em relação às instituições políticas com poder de decisão. $\mathrm{O}$ mecanismo de descentralização não pode ser entendido como um produto exclusivo do neoliberalismo. Em outras palavras, é perfeitamente possível apoiar medidas descentralizadoras sem que se tenha optado pelo modelo neoliberal (BORJA, 2016). Para Monlevade, as políticas macroeconômicas têm servido para legitimar as políticas antidemocráticas.

\begin{abstract}
Nos anos 1980, as políticas macroeconômicas adotadas pelas agências multilaterais têm servido para legitimar políticas sociais antidemocráticas, de subtração de investimentos dos serviços públicos; de aniquilamento das conquistas constitucionais; de redução da participação democrática e cidadã, de negação do direito de apropriação de bens culturais e educacionais pelos excluídos, enfim tem encontrado guarida num governo federal contraditoriamente autoritário e submisso. (MONLEVADE, 2000, p.14)
\end{abstract}

As manifestações do consentimento do governo federal são expressas, em primeiro lugar, pelo estreitamento das relações entre os gestores externos e nacionais, com a 
predominância dos interesses dos primeiros na elaboração de um conjunto de políticas de ajuste e de reformas, rigidamente controladas pelos dirigentes locais, para todos os setores.

Em segundo lugar, na assertiva de prioridade para a educação básica, inscrita nos documentos do Banco Mundial, que as difere das medidas aplicadas internamente no Brasil. A centralidade na concepção do Banco transforma-se na subtração de recursos orçamentários com insuficiente devolução aos Estados e municípios e na privatização gradual dos direitos constitucionais.

A descentralização é entendida como uma estratégia de gestão utilizada para propiciar a democratização do Estado e a busca de maior justiça social. Apesar das propostas de descentralização não serem novidades na administração pública, no contexto atual, ela é indicada como uma das alternativas de solução para o impasse em que se encontra o sistema educacional. Na ótica de Lobo, o impasse se verifica pela,

\footnotetext{
incapacidade do Estado em responder às mais prementes e agudas situações (...) incapacidade que surge de parcela da população, principalmente no que se refere ao atendimento de necessidades sociais básicas. Por isso não se aceita a desgastada ideia que justifica a não resposta do Estado exclusivamente pela escassez de recursos financeiros, ou pela priorização dada ao crescimento econômico frente às políticas sociais. (LOBO, 1990, p.6)
}

A esse respeito, Carnoy (1997) realça que a descentralização pode assumir formas variadas, dependendo da situação de desenvolvimento do país que a está utilizando. Por exemplo, países da Comunidade Europeia, quando utilizam a estratégia da descentralização, insistem fortemente em questões de controle administrativo e não tanto na questão da redução dos gastos ao erário.

Com essas reformas, o governo federal vem se desobrigando do financiamento das políticas educacionais universalistas, pois tem que racionalizar recursos, ao mesmo tempo em que objetiva centralizar as diretrizes, principalmente mediante os parâmetros curriculares nacionais e avaliação das instituições de ensino. Ou seja, definir o que vai ser ensinado em todas as escolas do País e ter o controle, por meio da avaliação institucional.

\section{Autonomia como instrumento de construção}


A participação e a autonomia correspondem a itens de fundamental importância para a representação na democracia, haja vista que se torna imperioso atribuir voz aos indivíduos de forma participativa e consciente. A participação se torna fundamental para o processo autônomo.

\subsection{Discutindo sobre a autonomia}

O conceito de autonomia aparece na literatura acadêmica, em algumas situações ligadas à ideia de participação da sociedade, em outros, à ideia de ampliação da participação política no que diz respeito à situação da descentralização e desconcentração do poder. Segundo Mendonça (1998, p.23), o próprio termo 'autonomia' já dar uma sinalização para o seu significado, assim,

o próprio conceito e o significado etimológico da palavra autonomia indicam uma importância dessa temática no contexto dos estudos sobre a gestão democrática do ensino público considerado fundamento constitucional da autonomia escolar. A autonomia é considerada liberdade ou independência moral e intelectual.

Barroso (1196b, p.17) observa que o conceito de autonomia está ligado à ideia de autogoverno em que os indivíduos são regulados por regras próprias. Contudo, isto não é sinônimo de indivíduos independentes. Para o autor,

a autonomia é um conceito relacional (somos sempre autônomos de alguém ou de algo), pois sua ação se exerce sempre num contexto de interdependência e processo de inter-relações. Também, a autonomia consiste em um conceito que exprime certo grau de relatividade: somos relativamente autônomos. A autonomia é uma maneira de gerir, orientar, as diversas dependências em que os homens e os grupos se relacionam no seu meio biológico ou social, de acordo com as suas próprias leis.

No âmbito do sistema educacional, a autonomia implantada na última década do século XX tem provocado modificações no espaço escolar. Essas transformações, segundo Barroso (1996), podem ser traduzidas em diferentes medidas que vão desde o reconhecimento e reforço da autonomia da escola, promoções de associação entre escolas e a sua integração em territórios mais amplos, até a adoção de modalidades específicas de gestão adaptadas às novas demandas da sociedade. 
O autor amplia o conceito de autonomia, afastando-se de uma visão restrita que privilegia a dimensão apenas jurídico-administrativa, que entende a autonomia pelo simples fato de serem decretadas as competências que são transferidas da administração central e regional para as escolas.

De acordo com Barroso (1996, c), a "autonomia da escola" resulta sempre da confluência de várias lógicas e interesses. É um campo de forças, em que se equilibram os diferentes detentores de poder destacando-se o governo, a administração, professores e outros membros da sociedade local. É por isso que a autonomia tem que ser criada em cada escola, privilegiando uma perspectiva mais sócio-organizacional, em que seja considerada um processo construído pela própria organização social e coerente com seus objetivos.

Barroso $(1996$, c) destaca alguns princípios básicos imprescindíveis ao delineamento da autoria no espaço escolar. São eles:

a) o reforço da autonomia da escola não pode ser definido de modo isolado, sem ter em conta outras dimensões complementares de um processo global de territorialização das políticas educacionais. Esse princípio significa que, ao transferir competências para as escolas, estas devem vir articuladas com medidas tomadas por todos os entes públicos. O projeto político seria um dos mecanismos viáveis para reforçar a autonomia da escola, mas as escolas públicas, muitas vezes, não estão preparadas para elaborá-lo.

b) no quadro do sistema público, 'a autonomia é sempre relativa' uma vez que é condicionada pelos poderes de tutela e de superintendência, seja do poder central ou local. De acordo com esse princípio, surgiria a necessidade de preservar e aumentar o papel regulador do Estado e de sua administração, com o fim de evitar a segmentação e pulverização do sistema de ensino.

c) uma política destinada a 'reforçar a autonomia das escolas' não pode se limitar à produção de um panorama legal que defina regras para a partilha de poderes e a distribuição de competências. Nesse sentido, não são as normas legais que irão possibilitar a autonomia, mas a criação de montagem de dispositivos que favoreçam condições para que as escolas construam sua autonomia.

d) o reforço da "autonomia" não pode ser considerado como uma "obrigação" para as escolas, mas sim como uma "possibilidade" que pretensamente venha a se concretizar na 
maioria dos casos. A própria escola deveria exprimir os anseios do processo de autonomia. Daí porque a autonomia não pode ser decretada.

e) o reforço da autonomia das escolas não constitui um fim em si mesmo, mas um meio de as escolas contribuírem com melhores condições na prestação do serviço público. Isto é, reside no fato de melhorar os índices de aproveitamento escolar, fazer-se respeitar os saberes prévios dos discentes e adquirir competências e técnicas previstas para o exercício da autonomia.

f) a autonomia é um investimento nas escolas, baseando-se em compromissos e benefícios. Para que a autonomia aconteça na escola, ela deve ser percebida em três aspectos: administrativo, financeiro e pedagógico. A escola não pode prescindir de um desses aspectos, sob pena de comprometer o processo da construção da autonomia. Os recursos financeiros são necessários para o desenvolvimento de ações. Saber gerir os recursos é essencial para o processo de autonomia da escola. Para que isso ocorra, é preciso estabelecer entre a administração e a escola um estreitamento na relação de confiança.

g) a autonomia também se aprende. Construir a autonomia implica "mudanças culturais" profundas nas pessoas e na cultura organizacional, logo, se verifica que a formação tem relevante papel nessa construção.

Bacelar (1997) acredita que a autonomia da escola só se concretizará se alguns requisitos forem atendidos, entre eles, o compromisso de todos, quando se encontram envolvidos no processo educativo. Isso não é impossível, mas é um processo muito lento, pela falta de conscientização política da maioria dos envolvidos que atuam na escola, pela capacidade de autocrítica, pelo espírito democrático objetivando fins coletivos em vez de individuais e conhecimento maior da problemática educacional brasileira e dos problemas locais onde se insere a escola.

Segundo Barroso (1996b), a autonomia escolar explicita duas vertentes: a primeira denomina-se jurídico-administrativo e a segunda, sócio-organizacional. A primeira dimensão diz respeito à competência que as escolas detêm para decidir sobre matérias administrativas e financeiras. Na segunda vertente, a autonomia recai sobre a dependência que as escolas estabelecem com o seu meio e que definem sua identidade. Sarmento (1998) afirma que as organizações escolares podem assumir diversas formas de controle, sob duas vertentes: formal-informal e a diacronia-sincronia. 
Nessa perspectiva, o autor destaca que, no cruzamento destas duas grandes vertentes, as escolas devem adquirir maneiras de regulação. No tocante à primeira vertente, que é a regulação normativa, correspondendo a um conjunto consignado de finalidade e intenções. A segunda forma é a regulação institucional, onde a tradição institucional, através das mais variadas formas, conduz a um alto grau de parâmetros simbólicos. A terceira é a função administrativa, onde se procura mobilizar os dispositivos e os recursos de ação para atingir determinados fins no contexto organizacional da escola. Finalmente, a quarta forma é a regulação contingencial, distinguindo-se das outras formas, pelo fato da regulação não se exercer sob a forma de normas, de comportamentos, de atitudes ou de atos administrativos, mas de se apresentar, sobretudo como dependente do momento e da situação.

Barroso (1996b) observa, também, que as escolas variam entre a heteronômica absoluta e a quase completa anomia (ausência de normas claras e comprometedoras, vivendo as escolas numa absoluta rotina), existindo, com isso, escolas que não sabem como desenvolver o trabalho escolar. Esse autor assinala ainda a existência de diversas situações onde os órgãos de gestão 'contornam' certos preceitos legais que impedem (ou dificultam) a tomada de decisão em domínios considerados estrategicamente importantes.

Este tipo de situação corresponde ao que Lima (1991) chama de infidelidades normativas e à qual Barroso (1996) denomina de autonomias clandestinas.

Nesse mesmo sentido, Barroso (1996a) alerta para os perigos de se ver a gestão com um fim em si, isto é, como um conjunto de princípios que podem ser generalizados, não tendo em conta a especificidade das organizações. Assim, destaca que a gestão da escola deve ser uma gestão adequada às características organizativas de uma escola. A escola é, pois, uma organização social onde coabitam pessoas das mais variadas faixas etárias (adultos, crianças, adolescentes, jovens); é uma organização com fins educativos, sendo o seu produto o crescimento dos alunos; e é uma organização com forte implantação social tendo uma finalidade objetiva, concreta e imediata, para as pessoas que vivem ali ao lado dela.

Desta forma, Barroso (1996a) considera que a autonomia da escola deve ser construída e não decretada. A autonomia da escola precisa ter em conta a especificidade da organização escolar, sendo construída pela interação dos diferentes atores organizacionais em cada escola. A interação destes diferentes atores conduz sempre a que se juntem diferentes interesses que são necessários saber articular. 


\subsection{Autonomia: estratégia negociável}

A participação é, pois, o resultado do equilíbrio de forças entre os diversos detentores de influência. A autonomia da escola pressupõe a participação dos seus atores. Segundo Barroso, a autonomia da escola precisa ser construída e não outorgada.

Mello (1998) destaca que a participação perpetua-se de forma harmoniosa no âmbito educacional, pois a participação não tende a ser mais uma utopia educacional e sim uma estratégia possível e negociável. Por isso, ela deve ser entendida como um processo que, no ritmo possível a cada correlação de forças políticas, conquiste a adesão de uns e os interesses de outros, pela vantagem que venha a apresentar em termos de resultados: ensino de melhor qualidade para todos. Torna-se cada vez mais difícil e ineficaz o controle centralizado e vertical das atividades-fim das organizações e sistemas, e isto é ainda mais verdadeiro para a estrutura do aparato estatal.

Não há respostas para as inúmeras e relevantes questões que se colocam diante das estratégias de descentralização e autonomia da escola. Há, todavia, de acordo com Melo (1998) alguns consensos e parâmetros que devem ser considerados. Dentre os consensos, a autora destaca os seguintes:

a) a estrutura dos sistemas de ensino se agigantou e se multiplicou. Essas burocracias centralizadas tornam-se fins em si mesmos. Há muito deixaram de ser apoio das atividadesfim e perderam de vista a unidade escolar que presta o serviço educacional. As escolas ordenam de cima para baixo ou do centro para a periferia. Vivem em função das normas externas. São controladas quanto aos aspectos formais e, ao mesmo tempo, abandonadas quanto aos aspectos substantivos;

b) o fortalecimento da unidade escolar exige que o que haja de melhor nos recursos humanos seja alocado às escolas, e que o investimento na atividade-fim aumente progressivamente. Assim, serão diminuídos os gastos com as múltiplas instâncias centrais, que funcionam para justificar sua própria existência e não efetivamente apoiar as escolas;

c) cada escola deve elaborar seu projeto institucional e pedagógico, mas isso requer capacitação e recursos financeiros. Ela deve ter poder de decisão sobre a alocação dos recursos, em função desse projeto. Essas condições não são dadas de imediato, e criá-las não é 
um processo rápido nem fácil. Será preciso dedicar tempo à investigação, à atuação políticoadministrativa e a programas de capacitação para qualificar a gestão escolar;

d) a autonomia da escola não é o descompromisso do governo com o ensino, nem da escola com seus alunos, todavia, são imprescindíveis diretrizes centrais básicas, comuns e também flexíveis sobre o que é essencial garantir para todos.

O grande desafio a ser enfrentado pelos dirigentes das instituições escolares diz respeito à construção da autonomia escolar e da gestão democrática, via participação, pois a centralização do sistema educacional encontra-se fortemente presente nos dias atuais.

Segundo Sá (2001), faz-se necessário mudar o sistema educacional vigente para que a autonomia e a participação sejam atingidas. É fundamental propor mudanças institucionais que possibilitem iniciativas para a autonomia e valorização da escola pública. E mudanças desta envergadura pressupõem critérios universalistas de repasse de recursos (em oposição aos clientelistas), e que estes recursos estejam à disposição das escolas para realizarem as atividades cotidianas. Requerem também que as estruturas centrais e intermediárias das secretarias de educação estejam organizadas para apoiar as atividades escolares.

\section{Representação e Democracia: questões conceituais}

Sem negar a estreita relação que há entre a educação e a formação democrática, não é possível restringir a ação política do indivíduo a serviços de interesses alheios, porque significaria renunciar a responsabilidade de construção de uma sociedade. Seria produzir sem apresentar resultados ou a conversão de cidadãos passivos e diminuídos, sem possibilidade nem capacidade de participar da construção da sociedade (BENEVIDES, 2018).

A representação, enquanto participação, corresponde a uma prática totalizadora e diária, que permite ao indivíduo conhecer e interagir na construção de uma sociedade mais participativa e consciente. Segundo Libâneo (2016), a participação representa uma concepção de escola democrática-participativa, que se baseia na relação orgânica entre direção e a participação do pessoal da escola. O autor acentua, ainda, a importância da busca de objetivos de gestão em que as decisões são tomadas coletivamente e discutidas publicamente. Entretanto, uma vez tomadas as decisões coletivamente, advoga que os membros da equipe assumam sua parte no trabalho, admitindo-se a coordenação e a avaliação sistemática da 
operacionalização das decisões tomadas dentro de uma real diferenciação de funções e saberes.

$\mathrm{Na}$ mesma lógica de pensamento, enfatiza o autor que o modelo democráticoparticipativo tem sido influenciado por uma corrente teórica que compreende a organização escolar como cultura. Esta corrente afirma que a escola não é uma estrutura totalmente objetiva, mensurável, independente das pessoas, ao contrário, ela depende muito das experiências subjetivas das pessoas e de suas interações sociais, ou seja, dos significados que as pessoas dão às coisas, enquanto significados socialmente produzidos e mantidos. Especificamente, a escola não é um ente isolado do contexto sócio-econômico e político, por isso, toda instituição escolar absorve e reflete as questões ocorridas extra-escola.

Segundo Keane (2018), a democracia corresponde a um substantivo feminino demokratiai, que surgiu de um desejo de resistência à tirania. $\mathrm{O}$ autor acrescenta que, possivelmente, Demonax tenha estado entre as primeiras figuras públicas a se descrever como amigo da democracia e que a palavra democracia é muito mais antiga do que os comentaristas clássicos gregos entreviam.

Ainda de acordo com Keane, a democracia significava a desnaturação do poder, e a luta constante era impedir o domínio dos poucos (ricos e poderosos) sobre a maioria. Por isso a democracia viria a ser o governo do humilde pelo humilde. As vozes-participação não poderiam ser mais dadas aos deuses, sob a alegação de que a democracia significava o autogoverno entre iguais com práticas de assembleias.

Essa igualdade participativa pressupõe um processo autônomo, no qual o homem tem liberdade para participar. Sob esse prisma, Neves (2015) argumenta que a autonomia, como liberdade, é um valor inerente ao ser humano: o homem não nasce para ser escravo ou tutelado, mas para ser livre.

\section{Considerações finais}

A participação deve envolver todos os atores sociais e garantir um planejamento no qual os diferentes olhares possam ser expressos. A criação de vínculos entre tais agentes torna-se necessário. O debate político expressa a democratização. 
A palavra autonomia deixou de ser entendida como se governa a si próprio, encontrando-se reduzida frente à ampliação de espaços de discussão interna à própria escola e limitada à liberdade de executar tarefas propostas pelo governo. Isso porque, medidas como a concessão de autonomia, a descentralização e a seleção de escolas 'bem sucedidas' por meio de avaliações externas a elas, configuram uma tendência nas diretrizes internacionais que orientam as reformas recentes das redes de ensino no Brasil. Tais concessões partem dos pressupostos identificados como mecanismos que permitem avaliar e controlar os produtos obtidos no processo educativo.

É importante sublinhar que, após décadas de cultura política centralizada e clientelista, não se pode reverter, magicamente, apenas pelo discurso oficial que defende a implementação da autonomia. A autonomia plena é inviável dentro da atual organização do sistema educacional que tem como preocupação a descentralização da execução de tarefas ao mesmo tempo em que busca manter o controle e o poder decisório. Dessa forma, a autonomia assume, no atual cenário, um caráter restrito que atende a lógica da política educacional vigente.

Os limites da autonomia escolar são demarcados pela relativa capacidade de decisão no âmbito interno da escola. O apoio técnico não tem autonomia de decisão, pois as decisões são hierarquizadas, onde os diretores recebem os programas em forma de pacotes prontos e acabados para serem executados. A partir daí, os professores tomam conhecimento e obedecem aos mandamentos educacionais que são postos como regras a serem exercidas.

As possibilidades dizem respeito à criação da autonomia, pois, como demonstrado, a autonomia precisa ser construída. Os atores escolares precisam estabelecer um processo de inter-relação e, concomitantemente, buscar um caminho autônomo, mesmo consciente de seus limites.

A construção de identidade pressupõe a participação de todos os atores que interagem entre si. A nova concepção das organizações implica a 'recuperação' da importância dos atores. Não se trata de uma concepção de racionalidade ilimitada, mas, sim, de uma concepção onde atores e sistema se condicionam mutuamente.

A autonomia da escola pública não pode estar associada a uma situação de afastamento das obrigações do Estado como provedor de condições mínimas para a existência e funcionamento da escola. Não existe autonomia da escola pública sem o devido custeio por parte do Estado.

Revista Brasileira de Filosofia do Direito | e-ISSN: 2526-012X | Belém | v. 5 | n. 2 | p. 108 - 124 | Jul/Dez. 2019. 
Apesar de o discurso ser favorável à autonomia, os sistemas de ensino continuam organizados para interagir com unidades escolares homogeneizadas por medidas lineares que atingem a todos igualmente. Livros, materiais pedagógicos, materiais de consumo e permanentes são distribuídos com base em modulações que consideram a quantidade de alunos, de profissionais e de salas de aulas da escola, além das modalidades de ensino desenvolvidas. Quase nunca, porém, têm em conta suas necessidades reais em face das realidades locais, do tipo de aluno, do projeto que pretende desenvolver.

Cabe realçar que, para a construção da autonomia, não basta um grande número de indivíduos que participem, direta ou indiretamente, da tomada de decisões coletivas. Não é suficiente, também, a existência de regras de procedimentos como a da maioria, isto é, da unanimidade. Torna-se indispensável, pois, uma terceira condição: é necessário que os agentes convidados ao processo de participação sejam colocados diante de condições reais para escolher entre uma e outra proposta. Para a efetivação dessa condição, é de fundamental importância que sejam garantidos aqueles que foram chamados a decidir, os denominados direitos de liberdade de opinião, de expressão, entre outros.

A autonomia não se define pela existência de um determinado ordenamento jurídico, ainda que este evidencie a relevância para uma maior dinâmica na autonomia das escolas. Em outras palavras, o processo de autonomia precisa se iniciar da dinâmica da escola na construção da sua identidade. Trata-se, pois, de mudanças de como a escola percebe o espaço de repetição, para a noção da escola como lugar de produção e inovação (BARROSO, 1996c).

Essa autonomia, porém, não deve ser confundida com metáforas a um trabalho "ilhado", desenhado por uma liberdade ilimitada, que transforme a escola em aspectos isolados de rituais sem fundamentação no ordenamento todo. Deve-se, portanto, estar atento ao perigo do descaso político que troca a autonomia pelo desinteresse do poder público, dando margem a este de eximir-se de suas obrigações.

Urge apresentar propostas que demonstrem realmente a construção de uma escola com a gestão democrática, fazendo com que os órgãos dirigentes da área educacional a reconheçam como prioridade e construam dispositivos legais que sejam justos, e disponibilizem recursos necessários para a construção do projeto da escola.

Para que a escola seja um lugar democrático e não se limite a copiar modelos de outras escolas, seguindo ordens a ela impostas por órgãos centrais da educação, é preciso criar um 
local para participação e reflexão coletiva sobre o seu papel junto à comunidade. Isso porque os princípios legais não são suficientes para decretar uma autonomia absoluta, tampouco a existência de um projeto engavetado e sem uma construção coletiva e participativa contribui para a obtenção dos objetivos proclamados. Autonomia é construção e não imposição.

\section{Referências}

BAUMAN, Zigmunt; BARDONI, Carlo. Estado de Crise. Trad. Renato Aguiar. Rio de Janeiro: Zahar, 2018.

BACELAR, Inalda Vieira. Escola, Descentralização e Autonomia. Revista de Administração Educacional. Departamento de Administração Escolar e Planejamento Educacional. Recife, v.1, p.27-37, jul. /dez.1997.

BARROSO, João. A escola e as lógicas da autonomia. Comunicação apresentada no Seminário promovido pelo Sindicato dos Professores do Norte, Maia, 1995.

O reforço da autonomia das escolas e a flexibilização da gestão escolar em Portugal. In: FERREIRA, Naura Syria Carapeto( Org.) gestão democrática da educação: atuais tendências, novos desafios. São Paulo: Cortez, 1998.

. Autonomia e gestão das escolas. Lisboa: Ministério da Educação. Estudo prévio realizado de acordo com o despacho $\mathrm{n}^{\circ}$ 130/ME/96,1996

BENEVIDES, Maria Victoria de Mesquita. A cidadania ativa; referendo, plebiscito, e iniciativa popular. São Paulo: Editora Ática, 2018.

BOBBIO, Noberto. O futuro da democracia. 2. ed. Rio de janeiro: paz e Terra, 1986. P. 1740: O futuro da democracia.

BORJA, Jordi. Descentralización Del estado - movimento social y gestión local. Santiago, ICI/ FLACSO/CLACSO, 2016.

BONAVIDES, Paulo. Teoria constitucional da democracia participativa. São Paulo: Malheiros Editores, 2001.

Revista Brasileira de Filosofia do Direito | e-ISSN: 2526-012X | Belém | v. 5 | n. 2 | p. 108 - 124 | Jul/Dez. 2019. 
CARNOY, Martin, CASTRO, Claúdio de M. A melhoria da educação na América Latina: e agora para onde vamos? In: CARNOY, Martin, Castro, Cláudio de M . (Org.). Como anda a reforma da educação na América Latina? Rio de Janeiro: FGV,1997.

KEANE, John. Vida e Morte da Democracia. Trad. Clara Colloto. São Paulo: Edições 7, 2018.

LIBÂNEO, José Carlos; OLIVEIRA, João Ferreria de; TOSCHI, Mirza Seabra. Educação Escolar: políticas, estrutura e organização. 10 ed. São Paulo: Cortez, 2016.

LIMA, L. Produção e reprodução de regras: normatismo e infidelidade normativa na organização escolar. Inovação, 4, p. 141-165. 1991.

LOBO, Maria Thereza. Descentralização: conceitos, princípios, prática governamental. Cadernos de pesquisa. Fundação Carlos Chagas, São Paulo, n. 74, p. 5-10, agosto, 2016.

LOBO, Heloísa H. de O, DIDONET, Vital. LDB: últimos passos no Congresso Nacional. São Paulo: Cortez, 1997.

MELLO, Guiomar Namo de. Cidadania e competitividade: desafios educacionais para o terceiro milênio. São Paulo: Cortez, 1998.

MENDONÇA, Erasto Fortes. A regra e o Jogo-Democracia e patrimonialismo na educação brasileira. 1998. São Paulo: LaPPlanE/ FE/ Unicamp

MONLEVADE, João A \& Silva. M. Abadia da. Quem manda na educação no Brasil?. Brasília-DF: Idéia editora: 2000.

MIGUEL, Luis Felipe. Democracia e Representação: Territórios em disputa. São Paulo: ed. Unesp, 2015.

NEVES, Carmen Moreira de Castro. Autonomia da Escola pública: Um enfoque operacional. In: VEIGA, I. P. A. (ORG). Projeto político-Pedagógico da escola: Uma construção possível. Magistério, formação e trabalho pedagógico. 2. ed. Campinas (SP): Papirus, 2015.cap. 4. p. 95-130.

SARTORI, Giovanni. A teoria da democracia revisitada. São Paulo: Ática, 1997, 2v.

OLIVEIRA, Cleiton de. Algumas considerações sobre a descentralização do ensino. Revista brasileira de administração da educação. ANPAE-Brasília-DF, v. 10, no 1, p. 1-94. Jan/ jun, 2010.

PEREIRA, Potyara A. P. A Assistência Social na perspectiva dos direitos. Crítica aos padrões dominantes de proteção aos pobres no Brasil. Brasília: Thesaurus, 2015.

Revista Brasileira de Filosofia do Direito | e-ISSN: 2526-012X | Belém | v. 5 | n. 2 | p. 108 - 124 | Jul/Dez. 2019. 
SA, Virgínio. A (não) participação dos pais na escola: A eloqüência das ausêncais. In: VEIGA, Ilma passos Alencastro \& FONSECA, Marília (Org). As dimensões do Projeto Político-Pedagógico. 1 ed. Campinas (SP): Papirus, 2001. Cap. 3.p. 69-103.

SARMENTO, M. Autonomia e regulação da mudança organizacional das escolas. Revista de Educação, vol. 7, nº 2, 1998. P.15-26.

UGA, Maria Alicia. Descentralização e democracia: o outro lado da moeda. In: Planejamento e políticas públicas. Brasília, n.5, p.87-104. 1991. 